\title{
Marc LEVATOIS, L'espace du sacré. Géographie intérieure du culte catholique
}

Paris, Éditions de l'Homme Nouveau, 2012, 148 p.

Philippe Martin

\section{(2) OpenEdition}

\section{Journals}

Édition électronique

URL : http://journals.openedition.org/assr/24025

DOI : $10.4000 /$ assr.24025

ISSN : $1777-5825$

Éditeur

Éditions de l'EHESS

Édition imprimée

Date de publication : 30 décembre 2013

ISSN : 0335-5985

\section{Référence électronique}

Philippe Martin, «Marc LEVATOIS, L'espace du sacré. Géographie intérieure du culte catholique », Archives de sciences sociales des religions [En ligne], 164 | 2013, mis en ligne le 03 décembre 2013, consulté le 21 septembre 2020. URL : http://journals.openedition.org/assr/24025 ; DOI : https:// doi.org/10.4000/assr.24025

Ce document a été généré automatiquement le 21 septembre 2020.

(c) Archives de sciences sociales des religions 


\section{Marc LEVATOIS, L'espace du sacré. Géographie intérieure du culte catholique}

Paris, Éditions de l'Homme Nouveau, 2012, 148 p.

Philippe Martin

\section{RÉFÉRENCE}

Marc LEVATOIS, L'espace du sacré. Géographie intérieure du culte catholique, Paris, Éditions de l'Homme Nouveau, 2012, 148 p. 
1 Le livre de Marc Levatois s'inscrit dans un courant historiographique qui, depuis le début $\mathrm{du} \mathrm{xx}^{\mathrm{e}}$ siècle, s'est lentement imposé : l'approche spatiale de la religion. Se concentrant sur le christianisme, plus particulièrement sur le catholicisme, l'auteur pose immédiatement une question : en quoi le sacré est-il chrétien? Pour y répondre, il convoque un grand nombre de références, présentées dans une bibliographie (non exhaustive et surtout francophone) qui occupe près de $8 \%$ des pages, et de longues citations

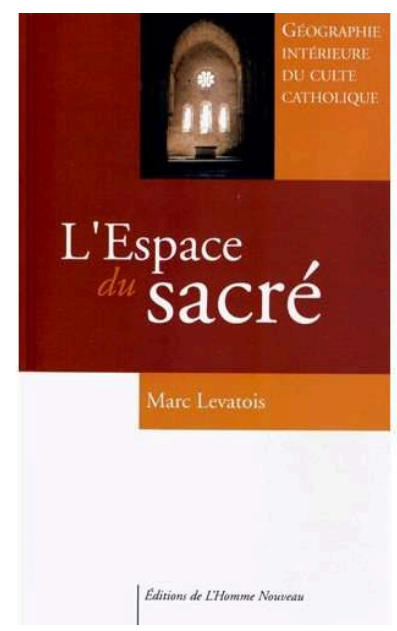
insérées dans le texte même. Les premiers chapitres sont une occasion de présenter l'émergence du sujet et ses inflexions actuelles; l'auteur en profite pour souligner l'importance de la pensée géographique, modelée en particulier par les travaux de Yi-Fu Tuan. Cette présentation débouche, parfois, sur des discussions précises, spécialement à propos des écrits du médiéviste Dominique Iogna-Prat sur la mise en place d'une organisation hiérarchisée des églises. Insensiblement apparaissent des définitions. La première met en place l'opposition et la complémentarité entre le « lieu saint », comme le pèlerinage, et le « lieu sacré ", tel un sanctuaire paroissial. À partir de là, Marc Levatois envisage l'espace sous toutes ses formes, n'hésitant pas à replacer le corps ou l'ouïe dans une économie générale de l'édifice de culte. Celui-ci se vit selon deux normes: la délimitation et l'orientation. Cette seconde notion tient à cœur à l'auteur. Il explique que le christianisme, en tournant édifices et rites vers le soleil levant, se distingue d'autres religions qui cherchent un point précis, que ce soit Jérusalem ou La Mecque. En se servant abondamment d'auteurs anciens (Durand de Mende ou Honorius d'Autun) et d'écrits de théologiens contemporains, il veut mettre en évidence l'existence d'une dynamique visant à imposer ce qu'il appelle l'« orientation effective stricte » (p. 102) : un édifice avec une abside tournée vers l'Est; des fidèles et un prêtre situés du même côté de l'autel regardant dans la même direction. Les variations qui existaient, en particulier à Rome durant l'Antiquité tardive et le haut Moyen Âge, auraient finalement été graduellement gommées, le Concile de Trente confirmant cette évolution. Cette spatialisation ordonnée du sacré se réaliserait pleinement dans la «messe dos au peuple ». Prenant le contre-pied de ce mouvement séculaire, le concile Vatican II aurait engendré une rupture fondamentale, favorisant une "atténuation du sacré » (p. 122). Mais son influence aurait commencé à décliner avec la réorientation du dialogue œcuménique par Jean-Paul II. Au lieu de discussions privilégiées avec le monde protestant occidental, qui, depuis le $\mathrm{XVI}^{\mathrm{e}}$ siècle, aurait une conception peu sacralisante de l'espace, il se serait rapproché des Églises orientales qui auraient conservé une certaine pureté de l'orientation.

2 L'auteur, selon ses propres termes, nous livre une "réflexion » (sic p. 131). Le lecteur qui cherche une approche chronologique globale du phénomène sera déçu par cet ouvrage qui se penche essentiellement sur les premiers temps du christianisme et le Moyen Âge pour arriver au monde très contemporain, sans avoir le temps de mesurer la profondeur des changements intervenus après le Concile de Trente. Il pourra aussi 
être surpris de ne pas voir développer différentes alternatives rituéliques, que ce soit la question de la célébration à l'extérieur d'un édifice, les réflexions liturgiques menées au sein de l'Église dans une perspective missionnaire outre-mer ou les recherches liturgiques à la suite des travaux de Pius Parsch. Sont aussi négligés de beaux textes spirituels qui donnent du souffle à ces questions. Lorsque, dans La messe sur le monde, Teilhard de Chardin assure à Dieu « je vous offrirai, moi votre prêtre, sur l'autel de la Terre entière", il développe une vision de l'espace sacré bien éloignée des problématiques d'orientation ou de délimitation. Études historiques ou anthropologiques ont déjà abordé ces points, prouvant que l'analyse de l'espace sacré est une des catégories fondamentales des sciences religieuses, comme l'a montré en 1987 Alphonse Dupront dans Du Sacré. 